\title{
The Surface Composition of Amino Acid - KCl solutions is $\mathrm{pH}$-Dependent
}

Geethanjali Gopakumar ${ }^{\mathrm{a}}$, Isaak Unger ${ }^{\mathrm{a},}{ }^{,}$, Clara-Magdelena Saak ${ }^{\mathrm{a}}$, Gunnar Öhrwallc ${ }^{\mathrm{c}}$, Arnaldo Naves de Brito ${ }^{\mathrm{d}}$, Tulio Costa Rizuti da Rocha ${ }^{\mathrm{e}}$, Christophe Nicolas ${ }^{\mathrm{f}}$, Carl Caleman ${ }^{\mathrm{a}, \mathrm{b},{ }^{*}}$ Olle Björneholm ${ }^{\mathrm{a},{ }^{*}}$

a Department of Physics and Astronomy, Uppsala University, Box 516, SE-751 20 Uppsala, Sweden

b Center for Free-Electron Laser Science, DESY, Notkestrasse 85, DE-22607 Hamburg, Germany

c MAX IV Laboratory, Lund University, PO Box 118, SE-22100 Lund, Sweden

d University of Campinas, Rua Sergio Buarque de Holanda, 777, Cidade Universitária 13083-970, Campinas, SP, Brazil

e Brazilian Synchrotron Light Laboratory (LNLS), Brazilian Center for Research in Energy and Materials (CNPEM), 13083-970, Campinas, Sao

Paulo, Brazil

f Synchrotron SOLEIL, L'Orme des Merisiers, Saint-Aubin - BP 48, 91192

Gif-sur-Yvette, France

* olle.bjorneholm@physics.uu.se, carl.caleman@physics.uu.se, isaak.unger@physics.uu.se

\section{Abstract}

In atmospheric aerosol particles, the chemical surface composition governs over both heterogenous chemical reactions with gas-phase species and the ability to act as nuclei for cloud droplets. The $\mathrm{pH}$ in aerosol droplets can be expected to affect these properties, but it is very challenging to measure the $\mathrm{pH}$ in individual droplets and thus little is known about its influence on the particle's surface composition. In this work, we explore with photoelectron spectroscopy how the surface composition of aqueous model solutions containing inorganic salt and amino acids changes as a function of $\mathrm{pH}$. We observe a change by a factor of 4-5 of the relative distribution of inorganic ions at the surface of a liquid water jet, as a function of solution $\mathrm{pH}$ and dependent on the amino acid in the solution. The driving forces for the surface enhancement or depletion are ion pairing and the formation of charged layers close to the aqueous surface. Our findings apply to any aqueous interface at which organic species with charged functional groups are present.

\section{Introduction}

Water is omnipresent in the earth's atmosphere as vapour, rain droplets or in aerosol particles of various origin. Depending on the source of the aerosol, their size and composition vary and they can pick up water while they are suspended in the atmosphere. Acting as cloud condensation nuclei [10, 11,35] and being substrates for 
chemical reactions at the particle-gas interface [14] are two of the most important roles of atmospheric aerosol and both strongly depend on their surface composition. A chemical reaction at the particle surface can only take place if the reactants are present, and the ability to act as cloud condensation nuclei is characterized by the hygroscopicity of the particles, which is also dependent on the chemical surface composition 35, 41.

The composition of aerosol particles in the atmosphere changes over time as they are exposed to chemical reactions and radiation. A prominent example of such processes is the ageing of sea spray aerosol. The longer sea spray aerosol particles remain suspended in the atmosphere, the more sulphuric and nitric acid they pick up, resulting in changes of their composition 2, 9]. Besides the composition, the $\mathrm{pH}$ of aqueous aerosol particles changes, too. Sea spray aerosol is produced from slightly basic sea water, but measurements of the aerosol $\mathrm{pH}$ indicate acidic conditions [15, 18, 19]. Measuring $\mathrm{pH}$ in aqueous aerosol is challenging since they are much smaller than the available probes. Only recently, some groups have begun to utilize spectroscopic techniques to measure the $\mathrm{pH}$ of aerosol 4 12 12 13. Moreover, Wei et al. found a $\mathrm{pH}$ gradient within basic aerosol particles 37 .

With the changing $\mathrm{pH}$ in the droplet, the protonation state of functional groups of solvated organic molecules changes and thus their charge state. Many of these molecules are surfactants and actively interact with inorganic ions present in the solution through their functional groups [6, 16, 33, and thus they potentially link the presence of inorganic ions at the surface to the $\mathrm{pH}$ of the particle, as the sketch in figure 1 implies. This link has implications in particular for chemical reactions at the particle surface, which involve inorganic ions. A prominent example for such a reaction is the production of $\mathrm{Cl}_{2}$ from $\mathrm{OH}_{\text {gas }}$ and $\mathrm{Cl}_{\text {surface }}^{-} 21$.

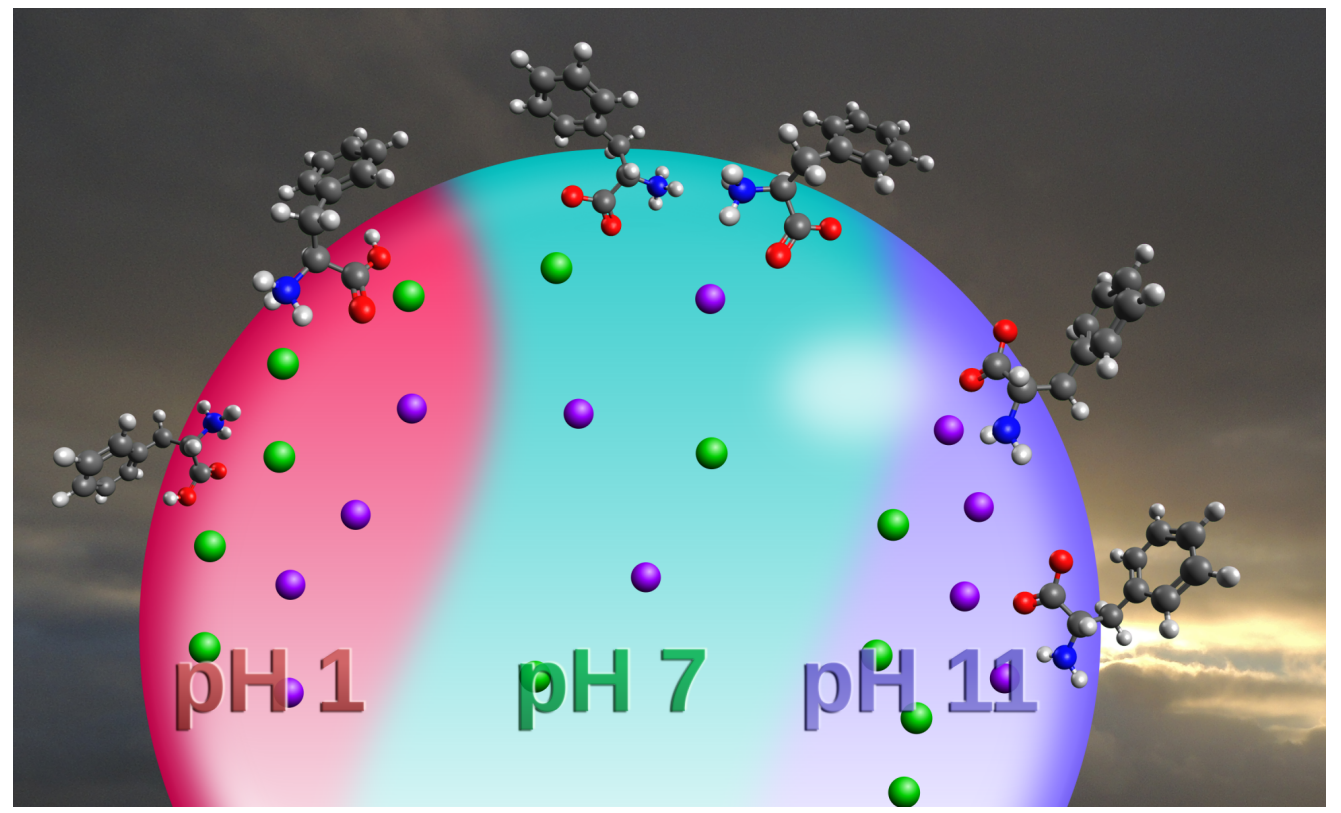

Figure 1. Organic surfactants in liquid aerosol, in this sketch phenylalanine, change the charge of their functional groups depending on the $\mathrm{pH}$ of the solution. Such changes influence the ions they interact with at the surface but to what degree?

To what degree the interaction between organic surfactants shapes the surface composition of a liquid as a function of $\mathrm{pH}$ is currently often unexplored. Our work attempts to fill this gap. We chose to use amino acids as organic component in our study as a place holder for organic solutes in aerosol due to many reasons. On one hand, 
amino acids are present in aerosol particles [36], and on the other hand, they possess two functional groups, which behave oppositely to changes of the $\mathrm{pH}$. Moreover, the surface propensity of different amino acids varies. By carefully selecting amino acids in our study, we aim to mimic a variety of other organic species present in aerosol with different surface propensity and charge. The focus of our interest here is on the behaviour of chloride, and we chose to use $\mathrm{KCl}$ in our study due to technical reasons, though $\mathrm{KCl}$ can be found at high concentrations in certain kinds of atmospheric aerosol [28,30].

\section{Results and Discussion}

We have used synchrotron-based X-ray photoelectron spectroscopy (XPS), an element-specific and surface-sensitive technique suitable for probing surfaces.

Photoelectron spectra of the K 2p, Cl 2p, C 1s, S 2p levels from the solutes and the valence levels of water were recorded. The data we show in the following originate from normalized fit area ratios of these spectra. Ratios in figures $2 \mathrm{p}$ and 3 are based on the ratio of the indicated peak areas, which reflect in the chemical composition of the surface. We describe the method of obtaining these ratios in more detail in the methods section and the supporting information.

\section{a}

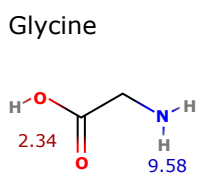

Valine

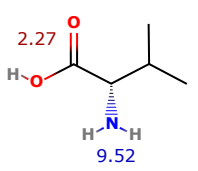

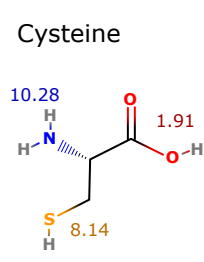

Phenylalanine

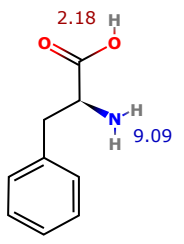

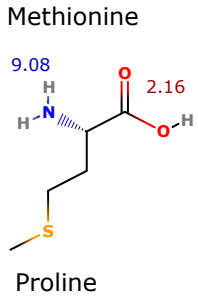

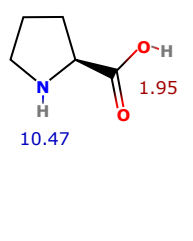

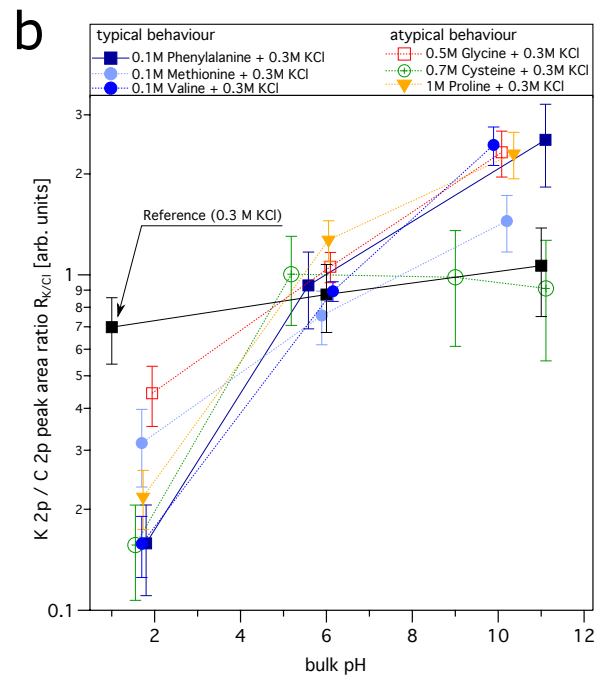

Figure 2. Figure 2 displays the structure of the amino acids used in this study. The $\mathrm{pK}_{a}$ values of their functional groups are depicted next to the respective groups [23]. The $\mathrm{K} 2 \mathrm{p} / \mathrm{Cl} 2 \mathrm{p}$ ratio $\left(R_{K / C l}\right)$ for the respective aqueous solutions is shown in $2 \mathrm{~b}$. All of the ratios have been derived from fits to the $\mathrm{K} 2 \mathrm{p}$ and $\mathrm{Cl} 2 \mathrm{p}$ levels recorded with XPS. We consider a solution containing only $0.3 \mathrm{M} \mathrm{KCl}$ (black squares) as a reference for the behaviour of $R_{K / C l}$ without the influence of surfactants. The behaviour of $R_{K / C l}$ in the presence of a surface enriched amino acid is best represented by the solution containing phenylalanine (dark blue squares). Due to the hydrophobic side chain, PHE is always enriched at the surface, which is not the case for all other amino acids we investigated here.

We used valine (VAL), methionine (MET), phenylalnine (PHE), cystiene (CYS), proline (PRO) and glycine (GLY) (figure 2a) in our study and the $\mathrm{pH}$ of the solution is adjusted such that at the particular $\mathrm{pH}$ all functional groups of an amino acid are either protonated or deprotonated (compare with $p K_{a}$ values given in figure $2 \mathrm{a}$ ). We

complement these data with a similar measurement of pure $0.3 \mathrm{M} \mathrm{KCl}$ reference solution. 
The $\mathrm{K} 2 \mathrm{p} / \mathrm{Cl} 2 \mathrm{p}$ ratios $\left(R_{K / C l}\right)$ in figure $2 \mathrm{p}$ show the relative surface distribution of the $\mathrm{K}^{+}$and $\mathrm{Cl}^{-}$of all samples for the respective $\mathrm{pH}$ values. The ratio for the reference solution changes slightly with values between $\sim 0.7$ and $\sim 1$. Taking into account the size of the error bars, this indicates that the surface propensity of $\mathrm{K}^{+}$and $\mathrm{Cl}^{-}$in a pure $\mathrm{KCl}$ solution does not change significantly with $\mathrm{pH}$. The solutions containing amino acids show deviations from the reference value for extreme $\mathrm{pH}$ values of the solution. At acidic $\mathrm{pH}$, where the functional groups of amino acids are protonated (-COOH and $-\mathrm{NH}_{3}^{+}$), $R_{K / C l}$ is lower than the reference value. At higher $\mathrm{pH}$, where the functional groups are deprotonated $\left(-\mathrm{COO}^{-}\right.$and $\left.-\mathrm{NH}_{2}\right), R_{K / C l}$ is significantly higher for all samples except CYS. Around $\mathrm{pH} 6$ the $\mathrm{K} 2 \mathrm{p} / \mathrm{Cl} 2 \mathrm{p}$ peak area ratio is similar to the reference within the error limits for all samples except PRO.

The difference ratio between the ion $2 \mathrm{p}$ levels and water $R_{\mathrm{H}_{2} \mathrm{O}}$ sheds further light on the ion distribution close to the liquid surface. The $R_{\mathrm{H}_{2} \mathrm{O}}$ in figure 3 are the comparison of either the $\mathrm{K} 2 \mathrm{p}$ or the $\mathrm{Cl} 2 \mathrm{p}$ signal with the signal from the $1 \mathrm{~b}_{1}$ level of liquid water, respectively. Furthermore, the value at $\mathrm{pH} \sim 6$ has been subtracted from the ones at acidic and basic $\mathrm{pH}$. In essence, figure 3 shows how much the ion / water ratio changes at acidic (basic) $\mathrm{pH}$ with respect to a solution at $\mathrm{pH} 6$.

We begin our discussion of the results with PHE, which we consider the clearest case. Phenylalanine has a very high surface propensity due to the large hydrophobic side chain (see figure 2a), and thus PHE is surface enriched in aqueous solution independently of the $\mathrm{pH}$. The changing charge of the functional groups of PHE therefore give rise to the formation of a charged layer at the liquid-gas interface. In acidic conditions, the net charge on PHE is positive due to the protonated amino group, which results in a positively charged surface layer. Hence, $\mathrm{K}^{+}$is repelled from the surface, and $R_{K / C l}$ drops below the reference value. At $\mathrm{pH} 5.58 \mathrm{PHE}$ is a zwitterion without net charge, and $R_{K / C l}$ is about the same as that of the reference solution. Neither of the inorganic ions is attracted to the surface beyond a level observable in the reference solution (black squares in figure $2 \mathrm{~b}$ ). Phenylalanine is an anion in a basic environment, and the solution possesses a negatively charged surface layer. Accordingly, $\mathrm{Cl}^{-}$is repelled from the surface, while $\mathrm{K}^{+}$is attracted. Ion pairing between $\mathrm{K}^{+}$and the carboxylate group of PHE might further support the presence of $\mathrm{K}^{+}$at the surface 27, 32. The $R_{\mathrm{H}_{2} \mathrm{O}}$ in figure 3 further clarifies that $\mathrm{Cl}^{-}$surface concentration increases in acidic conditions and decreases at basic $\mathrm{pH}$, while the surface concentration of $\mathrm{K}^{+}$follows the opposite trend.

The behaviour of $R_{\mathrm{H}_{2} \mathrm{O}}$ in PHE is shared by MET and VAL and their $R_{K / C l}$ (figure $2 \mathrm{p}$ ) also show a similar trend within limits. Accordingly, we assume that MET and VAL are also enriched at the aqueous surface between $\mathrm{pH} 1$ and $\mathrm{pH} 12$ and structure the $\mathrm{K}^{+}$ and $\mathrm{Cl}^{-}$concentration throught the same effects as PHE. Differences in $R_{K / C l}$ and $R_{\mathrm{H}_{2} \mathrm{O}}$ between PHE, MET and VAL are likely due to unequal absolute surface concentrations of the three amino acids.

CYS, GLY and PRO deviate from the behaviour of the other amino acids in one respect or another. While $R_{K / C l}$ of CYS is clearly below the reference value in acidic conditions, just as in the case of PHE, it does not increase above the reference value at high $\mathrm{pH}$ values. Instead, the $R_{K / C l}$ of CYS remains on approximately the same level as at $\mathrm{pH} \sim 5$. In GLY solutions the $R_{\mathrm{H}_{2} \mathrm{O}}$ partially deviates from the behaviour described for PHE. While $\mathrm{K}^{+}$is surface enriched in basic solutions, as is the case in $\mathrm{PHE}$, the $\mathrm{Cl}^{-}$ surface concentration does not increase in acidic conditions. Finally, the $R_{K / C l}$ of PRO differs from the behaviour of the other amino acids at around $\mathrm{pH} 6$ (see red triangles in figure $2 \mathrm{~b}$ ). In the following we will discuss possible reasons for the above differences for each amino acid separately.

We attribute the deviating behaviour of the $R_{\mathrm{H}_{2} \mathrm{O}}$ in CYS (figure 2p) to the thiol group in the side chain of CYS. The $\mathrm{pK}_{a}$ value of thiol functional group in cysteine is 
8.14 23, and at $\mathrm{pH}$ above 9 , the $\mathrm{CYS}$ solution contains some cysteine with $\mathrm{NH}_{3}^{+}, \mathrm{S}^{-}$ and $-\mathrm{COO}^{-}$5], resulting in a higher charge density on such molecules. These highly charged molecules interacts strongly with the surrounding water and it is energetically favourable for them to reside in the bulk of the solution. At $\mathrm{pH} 11$ the thiol groups of even more CYS molecules are deprotonated than at $\mathrm{pH}$ 9. This leads us to the conclusion that the behaviour of $R_{K / C l}$ in the CYS solution is governed by different processes, depending on the $\mathrm{pH}$ of the solution. At acidic $\mathrm{pH}$, the CYS molecules are slightly enriched at the liquid surface and the $-\mathrm{NH}_{3}^{+}$group attracts $\mathrm{Cl}^{-}$ions to the surface. This is supported by the $R_{\mathrm{H}_{2} \mathrm{O}}$ of $\mathrm{Cl}^{-}$depicted in figure 3 . At around $\mathrm{pH} 6$, CYS molecules possess no net charge and neither of the inorganic ions is attracted or repelled from the water surface. Deprotonation of the thiol group leads to an increase of the solubility of CYS at high $\mathrm{pH}$, and the amino acid is no longer surface enriched, therefore no longer impacts the $R_{K / C l}$.

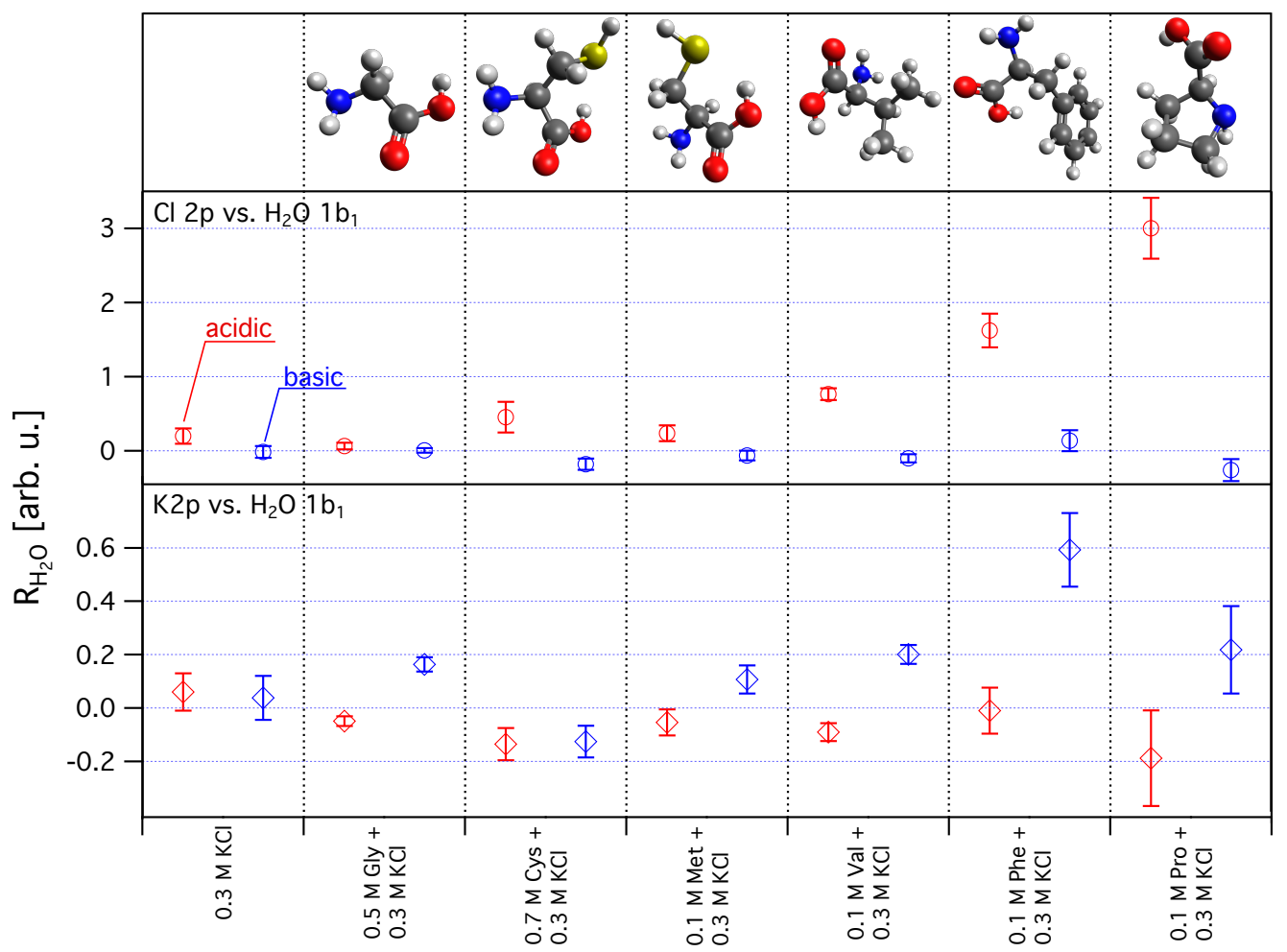

Figure 3. The $R_{\mathrm{H}_{2} \mathrm{O}}$ is the ratio between the peak area of $\mathrm{Cl} 2 \mathrm{p}$ ( $\mathrm{K} 2 \mathrm{p}$ ) levels and the water $1 \mathrm{~b}_{1}$ level relative to the same ratio at $\mathrm{pH}$ around 6 for each solution: $R_{H_{2} O}=\left(A_{K 2 p / C l 2 p} / A_{1 b_{1}}\right)_{p H X}-\left(A_{K 2 p / C l 2 p} / A_{1 b_{1}}\right)_{p H 6}$. Red symbols indicate values from acidic solutions, and blue ones from basic solutions. The first column depicts $R_{\mathrm{H}_{2} \mathrm{O}}$ for the reference solution (REF), and shows values around 0 . This indicates that the ion concentration with respect to water is similar at all $\mathrm{pH}$ values of the solution. The presence of most amino acids changes the concentration of $\mathrm{K}^{+}$and $\mathrm{Cl}^{-}$at the liquid surface, which is reflected in changes of the $R_{\mathrm{H}_{2} \mathrm{O}}$.

Glycine is the simplest amino acid with a 'side chain' containing H only. Simulations and experiments have shown that GLY remains mostly in the bulk 22, 25, yet we observe the $R_{K / C l}$ of co-solvated ions at surface is influenced by the presence of glycine (see figure $2 \mathrm{~b}$ ). The influence on $R_{K / C l}$ is more pronounced in basic solutions, where the impact of GLY is comparable to even the very surface enriched amino acids like PHE. At acidic $\mathrm{pH}$ the $R_{K / C l}$ in the glycine solution does not differ by a very large 
degree from the reference $\mathrm{KCl}$ solution. We speculate that the surface is not completely devoid of glycine molecules, and hence glycine interacts with the ions in close proximity. This interaction seems to affect the $\mathrm{K}^{+}$more strongly than the $\mathrm{Cl}^{-}$, which is also reflected in the $R_{\mathrm{H}_{2} \mathrm{O}}$. The interaction between the carboxylate group and inorganic cations has been reported before to have a profound influence on the surface structure of solutions containing long chain fatty acids 32] and we speculate that this is also the reason for the behaviour we observe here. Why glycine impacts the ion ratio close to the surface, however, remains elusive from our data.

The anomalous behaviour of PRO can be attributed to its molecular structure. Proline has the protonated NH group in a pyrrolidine ring side chain, and the positive excess charge upon protonation can be screened by $\pi$ electrons in the ring. Therefore the probability of the $-\mathrm{NH}_{2}^{+}$interacting with $\mathrm{Cl}^{-}$in acidic $\mathrm{PRO}$ solutions is lower as compared to the $-\mathrm{NH}_{3}^{+} \ldots \mathrm{Cl}^{-}$interaction for the other amino acids and what remains is the interaction between the carboxylate group and $\mathrm{K}^{+}$. This can also be seen from the $R_{\mathrm{H}_{2} \mathrm{O}}$ in figure 3, where the area of $\mathrm{K} 2 \mathrm{p}$ is much higher compared to other solutions and almost the same as that of $\mathrm{Cl} 2 \mathrm{p}$ peak area.

\section{Conclusions}

The $\mathrm{pH}$-dependent surface propensity of $\mathrm{K}^{+}$and $\mathrm{Cl}^{-}$in presence of amino acids is mediated by the charge state of the organic molecules if they reside at the surface of the solution. The $\mathrm{K}^{+}$and $\mathrm{Cl}^{-}$surface propensity in a co-solution of surface enriched PHE and $\mathrm{KCl}$ can be considered as a typical example. Due to the charge state of the amino acid, $\mathrm{Cl}^{-}$is surface enriched in acidic conditions, and surface depleted in basic conditions. $\mathrm{K}^{+}$follows the opposite trend, respectively. At neutral $\mathrm{pH}$, none of the inorganic ions is surface enriched with respect to the other. The driving force for this behaviour is the charge of the amino acid and ion pairing between the carboxylate group and $\mathrm{K}^{+}$. Co-solutions of $\mathrm{KCl}$ with either methionine or valine exhibit the same behaviour, co-solutions with glycine and proline show this effect to some degree. Cysteine, however, influences the $\mathrm{K}^{+} / \mathrm{Cl}^{-}$distribution differently close to the surface. This is attributed to a different screening of charges (proline) and the changing solubility of cysteine.

The potential implications of our findings for aqueous aerosol is the $\mathrm{pH}$-dependence of the surface composition, and hence on the chemistry related to aerosol surfaces in the atmosphere. In particular reactions involving halide ions at the particle surface will be affected. We have chosen to conduct our study using $\mathrm{KCl}$, where $\mathrm{Cl}^{-}$is a representative for halide ions. It is the most abundant of the three halides common in atmorpheric aerosol $\left(\mathrm{I}^{-}, \mathrm{Br}^{-}\right.$and $\left.\mathrm{Cl}^{-}\right)$but it is also the one that is expected to be the least surface enriched - and therefore it is particularly relevant to focus on how organic ions affect the surface enrichment of $\mathrm{Cl}^{-}$.

Our understanding of other processes sensitive to the surface composition of aerosol particles, like hygroscopic growth, will also benefit from our findings. Connected to hygroscopic growth is the ability of aerosol particles to act as cloud condensation nuclei and it may differ to what we can currently infer from their total chemical composition. Moreover, the change in $\mathrm{pH}$ may add a time development to these properties.

Studies such as ours should be expanded to divalent cations such as $\mathrm{Ca}^{2+}$ and a potentially stronger influence of ion pairing between the cation and the organic molecules. A pH dependence of the surface enrichment introduced to co-solvated organic molecules on anions with a high inherent surface propensity like $\mathrm{I}^{-}$or small organic acids is another area to explore with potentially far-reaching implications for our understanding of aqueous surfaces.

Though we sketch the ramifications of our findings for atmospheric chemistry here, 
the implications of our results are much broader. Any aqueous interface at which organic molecules interact with inorganic ions can potentially exhibit similar pH-driven effects.

\section{Materials and Methods}

Sets of XPS (X-ray Photoelectron Spectroscopy) measurements were carried out at the plane grating monochromator (PGM) U11 beamline of the Brazilian synchrotron light laboratory (LNLS) 8, with the SOL ${ }^{3}$ endstation 31] at the beamline U49-1 PGM1 at the synchrotron light source BESSY II 17], Berlin, Germany and at the beamline PLÉIADES (Polarized Light source for Electron and Ion Analysis from Diluted Excited Species) 24] of the synchrotron SOLEIL in France, using a liquid microjet set up at all three end stations.

The experimental setups at LNLS and at BESSY II are similar in design and have been described in previous publications in more detail 3. 31. Both machines utilize a High Pressure Liquid Chromatography (HPLC) pump to push the liquid solution from a reservoir through a quartz glass nozzle with inner diameter between $22-25 \mu \mathrm{m}$. Pump flow rates vary between $0.6-1 \mathrm{ml} / \mathrm{min}$ and a thin, liquid filament with laminar flow is created inside vacuum by the nozzle. The synchrotron radiation perpendicularly intersects and ionizes the sample about 1-2 mm downstream from tip of the nozzle, before the jet breaks into droplets. The emitted electrons pass through a skimmer which is mounted $2 \mathrm{~mm}$ away from the liquid surface, perpendicular to the direction of flow of the liquid jet and the direction of the synchrotron radiation. The kinetic energy of the electrons is measured using a hemispherical electron energy analyzer (Scienta Omicron R-4000 at LNLS, Scienta Omicron R-4000 HIPP-2 at BESSY II). The temperature of the jet is kept at $6^{\circ} \mathrm{C}$ before entering the vacuum chamber.

At SOLEIL, the photoelectron spectra were recorded using a wide-angle lens VG-Scienta R4000 electron spectrometer mounted in a $90^{\circ}$ angle relative to the polarization of the X-rays. The configuration of the microjet source coupled to the spectrometer is very similar to the one described in 7. Instead of a cold trap, a heated catcher of inner diameter about $500 \mu \mathrm{m}$ is employed to collect the used sample inside the vacuum chamber. The catcher is placed about $6 \mathrm{~mm}$ away from the glass nozzle and the liquid is pumped into a container outside the experimental chamber. Here, the sample is delivered into the experimental chamber through a glass nozzle of $40 \mu \mathrm{m}$ inner diameter using a HPLC pump at a flow rate of $1.4 \mathrm{ml} / \mathrm{min}$.

The sample solutions are prepared by dissolving commercially purchased potassium chloride $(\mathrm{KCl})$ (Alfa Aesar, purity $>98 \%$ ) and high purity amino acids (phenylalanine and cysteine from Sigma Aldrich with purity $>98 \%$; valine, glycine, proline and methionine from Alfa Aesar, purity >98\%) in MilliQ (18.2 M $/ \mathrm{cm}$ ) water. The pH of the sample solutions where adjusted using a strong acid $(\mathrm{HCl})$ and a strong base $(\mathrm{KOH}$ and $\mathrm{NaOH}$ ). The $\mathrm{pH}$ of the solution is adjusted such that at acidic $\mathrm{pH}$, it is below the $\mathrm{pK}_{a}$ value of carboxyl functional group of the respective amino acid. Likewise, in basic solutions the $\mathrm{pH}$ was kept above the $\mathrm{pK}_{b}$ of the amine groups. Measurements where also taken from samples without any further $\mathrm{pH}$ adjustments, resulting usually in a $\mathrm{pH}$ around 6. We term these conditions 'natural' $\mathrm{pH}$ throughout our paper. The concentration of the amino acids, the $\mathrm{pH}$ values used and the photon energy used for measurements are tabulated and presented in the Supplementary Information.

To remove all the solid particles which would block the flow in the microjet, all the samples are filtered using syringe filters with $0.45 \mu \mathrm{m}$ pore size prior to pumping it into the experimental chamber at LNLS. For the samples measured at SOLEIL, the solutions are filtered using filter paper of $6 \mu \mathrm{m}$ pore size. To determine the influence of amino acids on the surface propensity of ions, a reference sample of aqueous $0.3 \mathrm{M} \mathrm{KCl}$ solution is also measured. 
The surface enrichment of $\mathrm{K}^{+}$and $\mathrm{Cl}^{-}$in different amino acid solutions are monitored by measuring the signal from $2 p$ levels of potassium (binding energy $(\mathrm{BE}) \simeq$ $300.8 \mathrm{eV}, 298 \mathrm{eV})$ and chloride $(\mathrm{BE} \simeq 204.6 \mathrm{eV}, 203 \mathrm{eV})$ ion along with carbon $1 s$ signal. In addition to these orbitals for CYS and MET, sulfur $2 p$ is also probed.

The incident X-ray photon energy is kept constant for each set of measurements in order to avoid changes in photon flux due to movements of the beamline optics. This ensures that the intensities within one data set are comparable. This procedure results in varying electron kinetic energies for electrons originating from different atomic levels. Consequently, the electron mean free path of electrons originating e.g. from a $\mathrm{K} 2 \mathrm{p}$ level and a $\mathrm{Cl} 2 \mathrm{p}$ level are slightly different, however not to a degree that this effect invalidates our data 34$]$. A table with electron kinetic energies and the resulting estimates of the electron mean free path in liquid water is given in the SI. The energy calibration of the spectra is done against the $\mathrm{BE}$ of $1 b_{1}$ (highest occupied molecular orbital) of water. $(\mathrm{BE}=11.16 \mathrm{eV})[38$ to account for the generally unknown work function of the sample solution [26] and the streaming potential of the the jet [29].

The analysis of the spectra is carried out using Spectrum Analysis by Curve Fitting SPANCF 20] macro package for Igor Pro (Wavemetrics, Inc., Lake Oswego, USA). All the peaks are fitted using a Voigt profile where the Lorentzian width was set to $0.1 \mathrm{eV}$ and Gaussian profile was free to vary but kept same for the spin-orbit components of the peaks. Areas under the photoelectron (PE) peaks were determined from peak fits. The peak areas except the ones for the water $1 b_{1}$ level have further been normalized by molarity, photon flux and photoionization cross section. Data obtained from LNLS have further been normalized to the synchrotron ring current, as LNLS had been operated in decay mode, whereas the BESSY II and SOLEIL ran in top up mode. Data shown in figure $2 \mathrm{~b}$ has further been normalized to the variation of the asymmetry factors $(\beta)$ of $\mathrm{K}$ $2 \mathrm{p}$ and $\mathrm{Cl} 2 \mathrm{p}$ at different photon energies using the data base provided by [1] (table bases on [39,40]).

Error bars shown in the figures have been obtained from the fits to the measured data. A detailed description of this process, including figures of the intermediate steps, is provided in the supplementary information.

\section{Supporting Information}

\section{Fitting of the experimental data}

All experimental data have been fitted with Voigt profiles. Examples for the valence, $\mathrm{Cl}$ $2 \mathrm{p}, \mathrm{K} 2 \mathrm{p}, \mathrm{S} 2 \mathrm{p}$ (if applicable) and C 1s regions are shown in figure 4 . Valence band fits only served the purpose to obtain the area of the $1 b_{1}$ level of liquid water. As the valence data in figure 4 a) demonstrates, the signals from multiple levels overlap in the valence region, and one is forced to fit the entire valence region in order to attain the area of the liquid water $1 b_{1}$ level. The data shown in figure 4 originates from the LNLS, and the experimental resolution of these measurements was particularly low (compare peak width of the $1 b_{1}$ levels from the liquid and gas phase).

\section{Calculation of the Error Bars}

The fit errors given by the fitting packages we are using, SPAN-CF 20] and the Igor Pro built-in fit procedures, produce too small errors for the fit parameters. Often, even for a fit to very noisy data the errors on the fit parameters are extremely small and thus we decided to disregard these pre-build routines for the error estimation and employ a technique, which produces more plausible errors. The underlying idea is that the fit residue (i.e. the real data minus the fit to it) intrinsically contains the information 

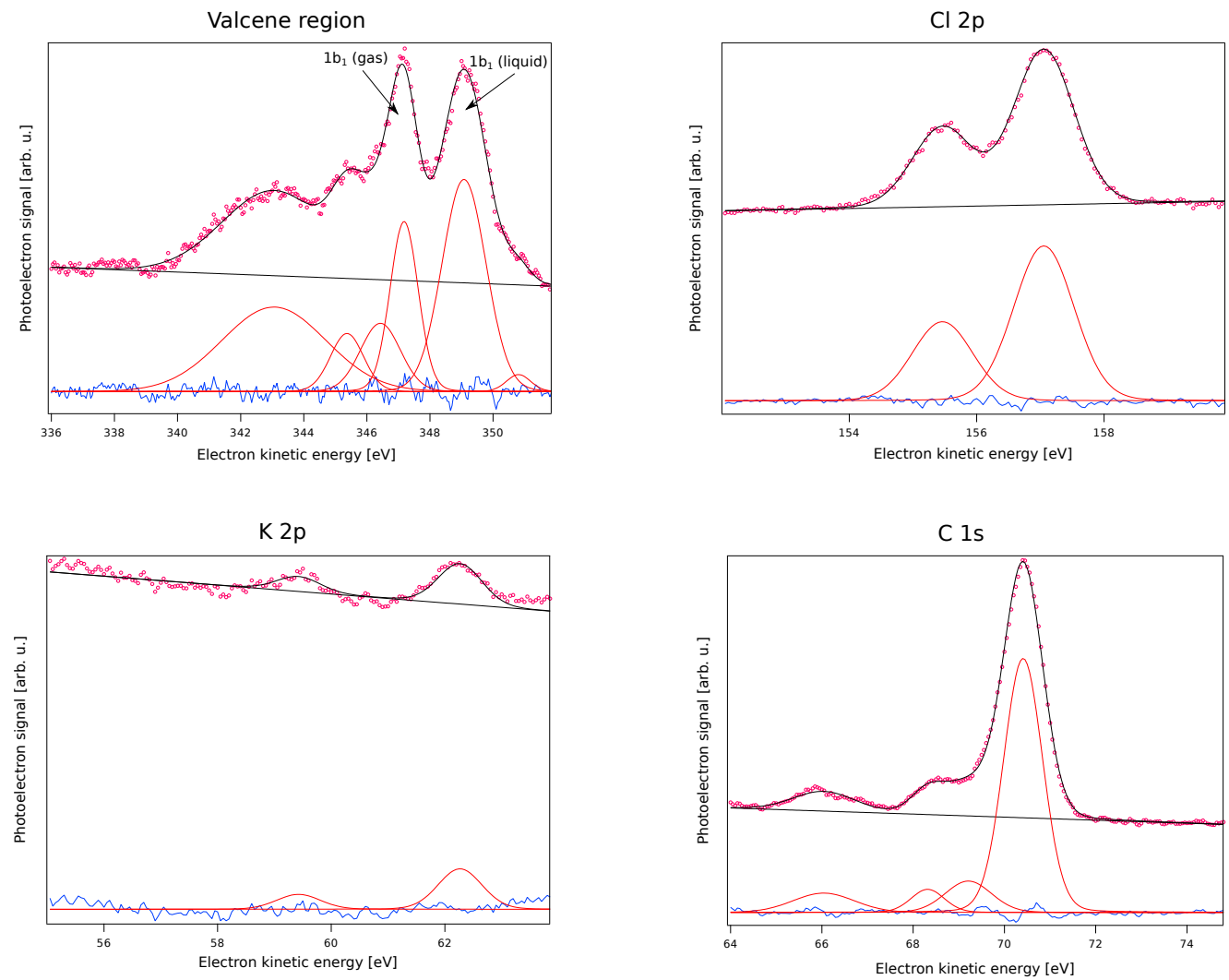

Figure 4. The panels above depict the fits to one data set $(0.1 \mathrm{M}$ Phe $+0.3 \mathrm{M} \mathrm{KCl}$ solution at $\mathrm{pH}$ 1.8; red circles). Data shown in these panels is shown as measured. i.e. no energy calibration or normalization has been applied. The blue curve at the bottom of the figure is the fit residue, which has been used subsequently to obtain error bars. 


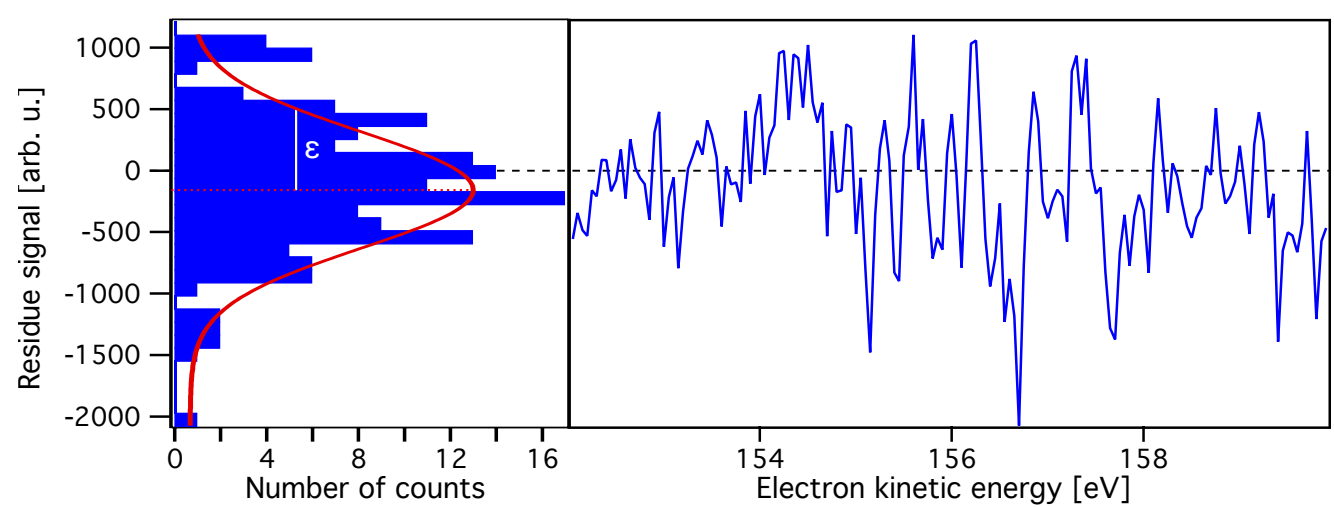

Figure 5. This is en example of a projection of the intensity values of a fit residuum being projected into a histogram. The fit residuum shown on the right originates from the fit of two Voigt profiles to the $\mathrm{Cl} 2 \mathrm{p}$ level of a $0.1 \mathrm{M}$ Phe $+0.3 \mathrm{M} \mathrm{KCl}$ solution at ph 1.8. The data including the fit is shown in figure 4. The data in the histogram is subsequently fit with a Gaussian, $2 \varepsilon$ is the full width at half maximum of the Gaussian.

about the range of the fit parameters. Therefore, our starting point is the fit residue and 'extract' a range for the fit parameters.

The first step is to sort all values on the ordinate of the fit residue into a histogram. We decided to sort the intensity values of the fit residue into 30 bins; an example of the resulting histogram together with the fit residue is shown in figure 5 for the chloride $2 \mathrm{p}$ level in a $0.1 \mathrm{M}$ Phe $+0.3 \mathrm{M} \mathrm{KCl}$ solution at $\mathrm{pH} 1.8$. The data in the histogram was fit with a Gaussian of which the full width at half maximum $(2 \varepsilon)$ is considered to be the range of the majority of the signal fluctuations in the measured data. Note that in this approach the background noise on the data as well as contributions to the fit residue due to inadequate fits are convoluted.

Since we consider $2 \varepsilon$ around the fit to represent the the interval in which most of the original data points can be found, we produce two artificial data sets from $\varepsilon$ and the original data in the following manner: In one case, we add $\varepsilon$ to the signal in the original data and in the other case we subtract $\varepsilon$ from the signal in the original data. The noise background of the original data remains unaltered by this procedure. Note that the criterion where the 'signal' separates from the 'background' is arbitrary to some degree. Here, we produced a linear fit using the average of the first five points and the last five points of each spectrum. Only if a point of the original data is $2 \varepsilon$ above that linear function, it is considered as 'signal'. This method assumes that the first and last points of a spectrum only contain background and no real signal, and that the background can be assumed to be a linar function. In our particular case, these assumptions hold, but they are not generally ture. The result of this procedure for the $\mathrm{Cl} 2 \mathrm{p}$ level of $0.1 \mathrm{M}$ Phe $+0.3 \mathrm{M} \mathrm{KCl}$ at $\mathrm{pH} 1.8$ is shown in figure 6 .

We fitted the artificial data sets anew, again with Voigt profiles. In these fits, we kept the peak positions fixed to the values we obtained from the fits to the original data, so that only the intensity and the broadening could vary - the two important parameters for the calculation of the peak area. Finally, we compared the peak areas of the fits to the original data with the two peak areas obtained from the fits to the artificial data. The larger difference between the peak area of the original data and the peak areas derived from the artificial data is considered to be the error. 


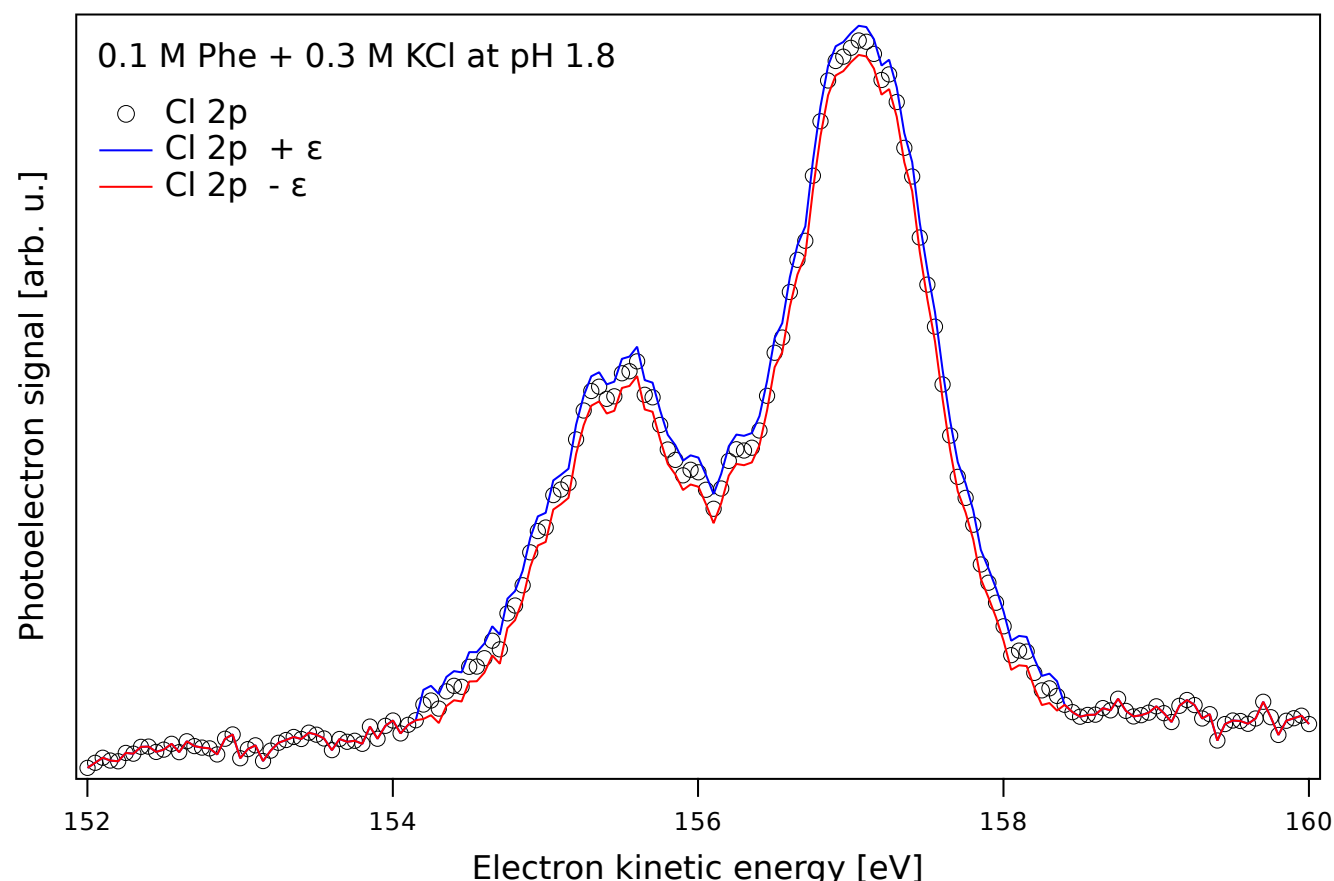

Figure 6. The figure above shows the original data and the two artificial data sets we produced from the fit residue.

\begin{tabular}{|c|c|c|c|c|c|c|}
\hline & \multicolumn{2}{|c|}{ LNLS } & \multicolumn{2}{c|}{ BESSY II } & \multicolumn{2}{c|}{ SOLEIL } \\
\hline & \multicolumn{2}{|c}{$\hbar \omega=360 \mathrm{eV}$} & \multicolumn{2}{c|}{$\hbar \omega=400 \mathrm{eV}$} & \multicolumn{2}{c|}{$\hbar \omega=420 \mathrm{eV}$} \\
\hline Level & $E_{k i n}[\mathrm{eV}]$ & MFP $[\mathrm{nm}]$ & $E_{k i n}[\mathrm{eV}]$ & MFP $[\mathrm{nm}]$ & $E_{k i n}[\mathrm{eV}]$ & MFP $[\mathrm{nm}]$ \\
\hline water $1 \mathrm{~b}_{1}$ & 349 & 1.86 & 389 & 2.06 & 409 & 2.17 \\
\hline $\mathrm{S} 2 \mathrm{p}$ & 197 & 1.30 & - & - & - & - \\
\hline $\mathrm{Cl} 2 \mathrm{p}$ & 158 & 1.25 & 198 & 1.31 & 218 & 1.35 \\
\hline $\mathrm{C} 1 \mathrm{~s}$ & 71 & 1.20 & 111 & 1.23 & 131 & 1.24 \\
\hline $\mathrm{K} 2 \mathrm{p}$ & 63 & 1.20 & 103 & 1.22 & 123 & 1.23 \\
\hline
\end{tabular}

Table 1. All numbers given for the electron mean free path (MFP) are estimates from 34 .

\section{Estimates of the Electron Mean Free Path / Probing Depth}

Due to the different binding energy of the atomic levels we probed X-rays of the same energy, the electrons originating from them have different kinetic energy, which results in a variation of the probing depth of our method depending on the kinetic energy of the electrons. In the energy regime we employed here, the difference in probing depth is negligible when comparing the signal from $\mathrm{K} 2 \mathrm{p}$ and $\mathrm{Cl} 2 \mathrm{p}$ levels. Comparison to the water $1 \mathrm{~b}_{1}$ state yields a small difference, but this leads to the resulting factor $\left(R_{\mathrm{H}_{2} \mathrm{O}}\right)$ underestimating the effect as the probing depth for electrons originating from the water valence band is higher. All values given in table 1 are estimates and base on the work of Thürmer et al. 34].

\section{Acknowledgments}

The authors acknowledge the beamtime granted (proposal ID 20180323 \& 20181440) at the synchrotron facilities SOLEIL, BESSY and LNLS. I.U. acknowledges the support

304 
from the Carl Tryggers Foundation and thanks Stephan Thürmer for his data analysis routines, which have been used for the data analysis. ANB acknowledges support from FAPESP (the Sao Paulo Research Foundation, Process number 2017/11986-5) and Shell and the strategic importance of the support given by ANP (Brazil's National Oil, Natural Gas and Biofuels Agency) through the R\&D levy regulation, and National Council for Scientific and Technological Development CNPq 401581/2016-0. We acknowledge support from the Swedish-Brazilian collaboration STINT-CAPES (9805/2014-01). C.C. acknowledges the Swedish Research Council (grant 2018-00740) and the Helmholtz Association through the Center for Free-Electron Laser Science at DESY. O.B. acknowledges the support by the Swedish Research Council (grant 2017-04162). Furthermore, we want to acknowledge the support of Johannes Kirschner, Christina Vantaraki, Rebecka Linnéa Lexelius, Hebatallah Ali, Aaron Ghrist, Florian Trinter, Flávio C. Vicentin and Bernd Winter during the beamtimes.

\section{References}

1. Elettra Web Cross Sections. https://vuo.elettra.eu/services/elements/WebElements.html, 2020. Accessed: 2020-09-10.

2. A. P. Ault, T. L. Guasco, O. S. Ryder, J. Baltrusaitis, L. A. Cuadra-Rodriguez, D. B. Collins, M. J. Ruppel, T. H. Bertram, K. A. Prather, and V. H. Grassian. Inside versus outside: Ion redistribution in nitric acid reacted sea spray aerosol particles as determined by single particle analysis. Journal of the American Chemical Society, 135:14528-14531, 2013.

3. H. Bergersen, R. Marinho, W. Pokapanich, A. Lindblad, O. Björneholm, L. Sæthre, and G. Öhrwall. A photoelectron spectroscopic study of aqueous tetrabutylammonium iodide. Journal of Physics: Condensed Matter, 19(32):326101, 2007.

4. H. C. Boyer, K. Gorkowski, and R. C. Sullivan. In situ pH measurements of individual levitated microdroplets using aerosol optical tweezers. Analytical Chemistry, 92:1089-1096, 2020.

5. V. Carravetta, A. Herbert de Abreu Gomes, S. Monti, A. Mocellin, R. R. T. Marinho, O. Björneholm, H. \{AAgren, and A. Naves de Brito. pH-dependent $\mathrm{X}$-ray photoelectron chemical shifts and surface distribution of cysteine in aqueous solution. The Journal of Physical Chemistry B, 123:3776-3785, 2019.

6. C. B. Casper, D. Verreault, E. M. Adams, W. Hua, and H. C. Allen. Surface potential of DPPC monolayers on concentrated aqueous salt solutions. The Journal of Physical Chemistry B, 120:2043-2052, 2016.

7. D. Céolin, N. Kryzhevoi, C. Nicolas, W. Pokapanich, S. Choksakulporn, P. Songsiriritthigul, T. Saisopa, Y. Rattanachai, Y. Utsumi, J. Palaudoux, et al. Ultrafast charge transfer processes accompanying KLL auger decay in aqueous KCl solution. Physical review letters, 119(26):263003, 2017.

8. J. Cezar, P. Fonseca, G. Rodrigues, A. De Castro, R. Neuenschwander, F. Rodrigues, B. Meyer, L. Ribeiro, A. Moreira, J. Piton, et al. The U11 PGM beam line at the brazilian national synchrotron light laboratory. In Journal of Physics: Conference Series, volume 425, page 072015. IOP Publishing, 2013. 
9. J. W. Chi, W. J. Li, D. Z. Zhang, J. C. Zhang, Y. T. Lin, X. J. Shen, J. Y. Sun, J. M. Chen, X. Y. Zhang, Y. M. Zhang, and W. X. Wang. Sea salt aerosols as a reactive surface for inorganic and organic acidic gases in the arctic troposphere. Atmospheric Chemistry and Physics, 15:11341-1135, 2015.

10. M. W. Christensen and G. L. Stephens. Microphysical and macrophysical responses of marine stratocumulus polluted by underlying ships: Evidence of cloud deepening. Journal of Geophysical Research, 116:D03201, 2011.

11. M. W. Christensen and G. L. Stephens. Microphysical and macrophysical responses of marine stratocumulus polluted by underlying ships: 2. Impacts of haze on precipitating clouds. Atmospheric Chemistry and Physics, 117:D11203, 2012.

12. E. M. Coddens, K. J. Angle, and V. H. Grassian. Titration of aerosol pH through droplet coalescence. The Journal of Physical Chemistry Letters, 10(15):4476-4483, 2019.

13. R. L. Craig, L. Nandy, J. L. Axson, C. S. Dutcher, and A. P. Ault. Spectroscopic determination of aerosol $\mathrm{pH}$ from acidbase equilibria in inorganic, organic, and mixed systems. The Journal of Physical Chemistry A, 121:5690-5699, 2017.

14. B. J. Finlayson-Pitts. Reactions at surfaces in the atmosphere: integration of experiments and theory as necessary (but not necessarily sufficient) for predicting the physical chemistry of aerosols. Physical Chemistry Chemical Physics, 11(36):7760, sep 2009.

15. A. Fridlind and M. Z. Jacobson. A study of gas-aerosol equilibrium and aerosol $\mathrm{pH}$ in the remote marine boundary layer during the first aerosol characterization experiment (ace 1). Journal of Geophysical Research, 105:17325-17340, 2000.

16. W. Hua, D. Verreault, and H. C. Allen. Solvation of calcium-phosphate headgroup complexes at the DPPC/aqueous interface. ChemPhysChem, 16:3910-3915, 2015.

17. T. Kachel. The plane grating monochromator beamline U49/2 PGM1 at BESSY II. Journal of large-scale research facilities, 2:A72, 2016.

18. W. C. Keene, A. A. P. Pszenny, J. R. Maben, and R. Sander. Variation of marine aerosol acidity with particle size. Geophysical Research Letters, 29:1101, 2002.

19. W. C. Keene, A. A. P. Pszenny, J. R. Maben, E. Stevenson, and A. Wall. Closure evaluation of size-resolved aerosol $\mathrm{pH}$ in the new england coastal atmosphere during summer. Journal of Geophysical Research, 109:D23307, 2004.

20. E. Kukk. Spectrum analysis by curve fitting (spancf)-macro package for igor pro, 2012 .

21. A. Laskin, H. Wang, W. H. Robertson, J. P. Cowin, M. J. Ezell, and B. J. Finlayson-Pitts. A new approach to determining gas-particle reaction probabilities and application to the heterogeneous reaction of deliquesced sodium chloride particles with gas-phase hydroxyl radicals. The Journal of Physical Chemistry A, 110:10619-10627, 2006.

22. X. Li, T. Hede, Y. Tu, C. Leck, and H. Ågren. Cloud droplet activation mechanisms of amino acid aerosol particles: insight from molecular dynamics simulations. Tellus B: Chemical and Physical Meteorology, 65(1):20476, 2013. 
23. D. R. Lide. CRC handbook of chemistry and physics, Internet Version. CRC Press, CRC Press, Boca Raton, FL, 2005.

24. A. Lindblad, J. Söderström, C. Nicolas, E. Robert, and C. Miron. A multi purpose source chamber at the PLEIADES beamline at SOLEIL for spectroscopic studies of isolated species: Cold molecules, clusters, and nanoparticles. Rev. Sci. Instrum., 84(11):113105, 2013.

25. A. Mocellin, A. Herbert de Abreu Gomes, O. C. Araujo, A. Naves de Brito, and O. Björneholm. Surface propensity of atmospherically relevant amino acids studied by XPS. The Journal of Physical Chemistry B, 121(16):4220-4225, 2017.

26. G. Olivieri, A. Goel, A. Kleibert, D. Cvetko, and M. A. Brown. Quantitative ionization energies and work functions of aqueous solutions. Physical Chemistry Chemical Physics, 18:29506-29515, 2016.

27. S. T. Pastorczak, Marcinand van der Posta and H. J. Bakker. Cooperative hydration of carboxylate groups with alkali cations. Physical Chemistry Chemical Physics, 15:17767-17770, 2013.

28. M. Pósfai, R. Simonics, J. Li, P. V. Hobbs, and P. R. Buseck. Individual aerosol particles from biomass burning in southern africa: 1. Compositions and size distributions of carbonaceous particles. Journal of Geophysical Research: Atmospheres, 108(D13), 2003.

29. N. Preissler, F. Buchner, T. Schultz, and A. Lübcke. Electrokinetic charging and evidence for charge evaporation in liquid microjets of aqueous salt solution. The Journal of Physical Chemistry B, 117:2422-2428, 2013.

30. J. Rissler, J. Pagels, E. Swietlicki, A. Wierzbicka, M. Strand, L. Lillieblad, M. Sanati, and M. Bohgard. Hygroscopic behavior of aerosol particles emitted from biomass fired grate boilers. Aerosol Science and Technology, 39:919-930, 2005.

31. R. Seidel, M. N. Pohl, H. Ali, and E. F. Aziz. Advances in liquid phase soft-x-ray photoemission spectroscopy: A new experimental setup at BESSY II. Review of Scientific Instruments, 88:073107, 2017.

32. C. Y. Tang and H. C. Allen. Ionic binding of $\mathrm{Na}^{+}$versus $\mathrm{K}^{+}$to the carboxylic acid headgroup of palmitic acid monolayers studied by vibrational sum frequency generation spectroscopy. The Journal of Physical Chemistry A, 113:7383-7393, 2009.

33. C. Y. Tang, Z. Huang, and H. C. Allen. Interfacial water structure and effects of $\mathrm{Mg}^{2+}$ and $\mathrm{Ca}^{2+}$ binding to the $\mathrm{COOH}$ headgroup of a palmitic acid monolayer studied by sum frequency spectroscopy. The Journal of Physical Chemistry B, 115:34-40, 2011.

34. S. Thürmer, R. Seidel, M. Faubel, W. Eberhardt, J. C. Hemminger, S. E. Bradforth, and B. Winter. Photoelectron angular distributions from liquid water: Effects of electron scattering. Pysical Review Letters, 111:173005, 2013.

35. O. Väisänen, A. Ruuskanen, A. Ylisirniö, P. Miettinen, H. Portin, L. Hao, A. Leskinen, M. Komppula, S. Romakkaniemi, K. E. J. Lehtinen, and A. Virtanen. In-cloud measurements highlight the role of aerosol hygroscopicity in cloud droplet formation. Atmospheric Chemistry and Physics, 16:10385-10398, 2016. 
36. M. A. Wedyan and M. R. Preston. The coupling of surface seawater organic nitrogen and the marine aerosol as inferred from enantiomer-specific amino acid analysis. Atmospheric Environment, 42(37):8698-8705, 2008.

37. H. Wei, E. P. Vejerano, Q. Leng, Weinan Huang, M. R. Willner, L. C. Marr, and P. J. Vikesland. Aerosol microdroplets exhibit a stable pH gradient. PNAS, 115:7272-7277, 2018.

38. B. Winter, R. Weber, W. Widdra, M. Dittmar, M. Faubel, and I. Hertel. Full valence band photoemission from liquid water using EUV synchrotron radiation. The Journal of Physical Chemistry A, 108(14):2625-2632, 2004.

39. J. J. Yeh. Atomic Calculation of Photoionization Cross-Sections and Asymmetry Parameters. Gordon and Breach Science Publishers, Langhorne, PE (USA), 1993.

40. J. J. Yeh and I. Lindau. Atomic subshell photoionization cross sections and asymmetry parameters: 1z103. Atomic Data and Nuclear Data Tables, 32:1-155, 1985.

41. P. Zieger, O. Väisänen, J. C. Corbin, D. G. Partridge, S. Bastelberger, M. Mousavi-Fard, B. Rosati, M. Gysel, U. K. Krieger, C. Leck, et al. Revising the hygroscopicity of inorganic sea salt particles. Nature communications, 8:15883, 2017. 